\title{
Para vaginal dermoid cyst: a rare occurrence
}

\section{Ruby Bhatia ${ }^{1 *}$, Manjit Kaur Mohi², Anju Gupta ${ }^{2}$, Sonia Goyal ${ }^{2}$}

\author{
${ }^{1}$ Department of Obstetrics and Gynecology, MM (DU), Mullana, Ambala, Haryana, India \\ ${ }^{2}$ Department of Obstetrics and Gynecology, GMC, Patiala, Punjab, India
}

Received: 22 November 2018

Accepted: 29 December 2018

\author{
*Correspondence: \\ Dr. Ruby Bhatia, \\ E-mail: drrubybhatia@yahoo.com
}

Copyright: (c) the author(s), publisher and licensee Medip Academy. This is an open-access article distributed under the terms of the Creative Commons Attribution Non-Commercial License, which permits unrestricted non-commercial use, distribution, and reproduction in any medium, provided the original work is properly cited.

\begin{abstract}
Dermoid cyst (cystic teratoma) showing well differentiated derivatives of all three germs cell layers, is a benign germ cell tumour. Ovaries remain the commonest site. Paravaginal dermoid cyst is a rare occurrence. Pre-operative diagnosis is usually difficult in majority of cases. They constitute less than $4 \%$ of all extragonadal teratomas. A $28-$ year old, $\mathrm{P}_{2} \mathrm{~L}_{2}$ female presented with paravaginal cyst, $10 \times 10 \mathrm{cms}$, non-tender, soft swelling, cystic in consistency occupying posterior and left part of rectovaginal septum. Trans vaginal excision of cyst under regional anaesthesia done. Cyst was ruptured while excision showing putty material with tuft of hairs. A retrospective diagnosis of mature teratoma/paravaginal dermoid cyst was made on histopathological examination. Paravaginal dermoid cyst, a benign cystic teratoma is a very rare occurrence. Transvaginal excision of dermoid cyst under anaesthesia remains treatment of choice. Retrospective diagnosis on histopathological examination remains confirmatory as it may be missed on sonography if teeth are not present in dermoid cyst.
\end{abstract}

Keywords: Benign, Dermoid cyst, Paravaginal, Teratoma

\section{INTRODUCTION}

Paravaginal dermoid cyst is a rare entity in gynecological practice. Dermoid cyst (cystic teratoma) showing well differentiated derivatives of all three germs cell layers is a benign germ cell tumour. Ovaries remain the commonest site. $80 \%$ of benign dermoid cyst of ovary are seen in reproductive age group. In girls younger than twenty years of age, dermoid cyst accounts for more than half of ovarian neoplasms. ${ }^{1}$ Dermoid cyst occur usefully at birth or early childhood along line of embryonic fusion over head, neck, mediastinum and presacral area. ${ }^{2}$ Paravaginal dermoid cyst constitutes less than $4 \%$ of all extra-gonadal teratomas. Till date only 7 cases of paravaginal dermoid cyst have been reported in the literature. ${ }^{2}$ Pre-operative diagnosis of the exact nature of vaginal cyst may be difficult. Vaginal dermoid cyst was first reported in a 44year old woman with one cm cyst just within hymen.
The cyst on excision shows sebaceous glands and hair follicles. ${ }^{3}$ When teeth also form part of vaginal dermoid cyst it is called vagina dentata-a universal symbol of men's fear of women. ${ }^{4}$ Siu et al, presented pre-operative ultrasound findings consistent with dermoid cyst of vagina. Hence, transvaginal ultrasound remains gold standard as a diagnostic tool when teeth /bone are present in dermoid cyst. Trans-vaginal surgical excision remains treatment of choice for para-vaginal dermoid cyst. Retrospective diagnosis on histopathology is confirmatory. If teeth are absent in dermoid cyst, the diagnosis may be missed on ultrasonography. Complete excision of paravaginal dermoid cyst has good prognosis.

\section{CASE REPORT}

A 28-year-old $\mathrm{P}_{2} \mathrm{~L}_{2}$ presented in gynecology outpatient department of Government Medical College, Rajindra 
Hospital, Patiala on $1^{\text {st }}$ June 2017 with pelvic pain, feeling of pressure with heaviness in perineum and dyspareunia for last one year. There was no history of local trauma. On per speculum examination, cervix was healthy.

Pelvic examination revealed $10 \times 10 \mathrm{~cm}$ soft-cystic, nontender swelling in posterior and left half of vagina, with restricted mobility protruding through postero-lateral vaginal mucosa towards left side, extending up to vaginal vault in left lateral fornix. On per rectal examination, mass was occupying left paravaginal space, anterior to rectum extending into left ischiorectal fossa. Patient came with MRI Pelvis dated $21^{\text {st }}$ January 2016 showed normal uterus and bilateral ovaries. There was $9.3 \times 7.8 \times 7.3 \mathrm{~cm}$ space occupying lesion in left ischiorectal fossa. A diagnosis of paravaginal cyst was made.

Transvaginal excision of paravaginal cyst under regional anesthesia was planned after preoperative workup and necessary investigations. Bimanual pelvic and rectal examination was repeated under regional anesthesia to confirm the extension of cyst. Posterior vaginal mucosa over the cyst was infiltrated with 1:10 vasopressin solution. $5 \mathrm{~cm}$ long vertical incision was given in vaginal mucosa overlying cyst.

The cyst was separated from vaginal mucosa by blunt and sharp dissection. Cyst was adherent with rectum and separated with great difficulty with assistant's finger in rectum during the procedure. Cyst ruptured during excision due to dense adhesions with rectum. Thick cheesy putty material with matted tufts of hair confirmed diagnosis of dermoid cyst (Figure 1).

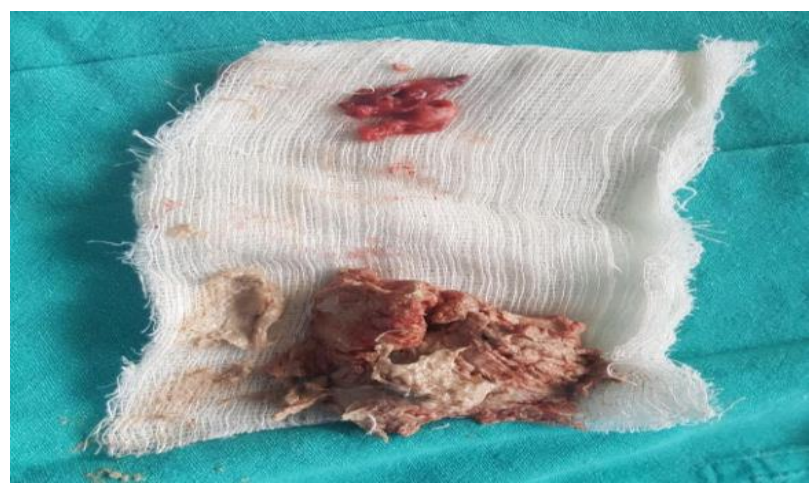

Figure 1: Thick cheesy putty material with matted tufts of hair in ruptured paravgainal cyst.

Surgery completed maintaining complete hemostasis. Dead space packed tightly with four vaginal packs. Inj cefaperazone 1gram intravenous 12-hourly given for 72hours. Packs removed after 48hours. Histopathological examination revealed cysts lined by stratified squamous epithelium. Underneath seen skin, smooth muscle, mature neural tissues, keratin flakes and fibro collagenous stroma confirming diagnosis of dermoid cyst/mature teratoma (Figure 2 and 3).

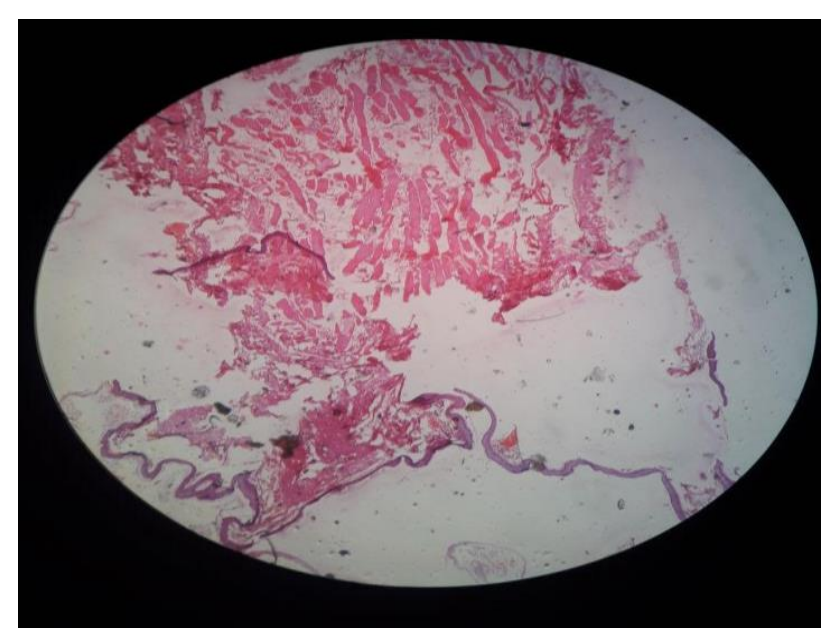

Figure 2: Histopathological examination showing well differentiated tissues of three germ cell layersstratified squamous epithelial lining.

Post-operative repeat MRI whole abdomen and pelvic organs dated $13^{\text {th }}$ June 2017 confirmed normal bilateral ovaries with no evidence of any other dermoid cyst in gonadal or extragonadal areas. Post-operative period was uneventful. Patient was discharged on $7^{\text {th }}$ post-operative day. On follow up till date there are no complaints.

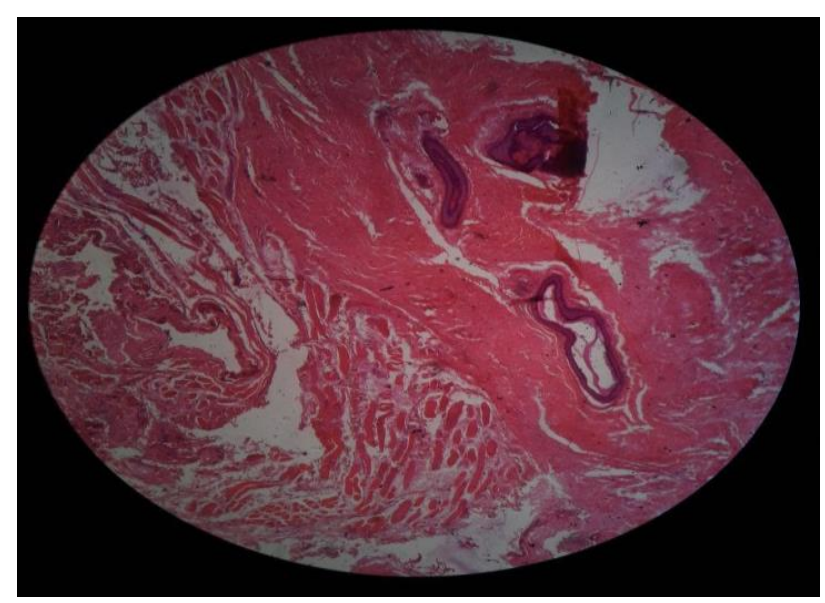

Figure 3: Histopathological examination showing well differentiated tissues of three germ cell layers-gland, muscle, keratin and fibro collagen skin, smooth muscle tissue and keratin.

\section{DISCUSSION}

Dermoid cyst with well-differentiated derivatives of all three-germ cell layer is a benign germ cell tumour, the commonest site being ovaries. More than $50 \%$ of ovarian tumour in young girls $<20$ years is dermoid cyst. $80 \%$ of dermoid cyst in ovary are seen in reproductive phase of life. ${ }^{1}$ A dermoid cyst can also be present from floor of mouth until colon in gastrointestinal tract..$^{5-7}$ As dermoid cyst arises from outer layers of embryonic skin cells which has capacity to mature into hair, teeth or bone thereby making possible to be diagnosed by sonography. 
Vaginal dermoid cyst is well demarcated from surrounding vaginal tissues and its contents are hetero echogenic on transvaginal sonography. ${ }^{4}$ Presence of teeth in vaginal dermoid cyst is defined as vagina dentata-a feature of men's fear of women. With creation of myths and folk stories in culture of native Americans and different areas of Russia, Japan, India and New Zealand vagina dentata was interpreted as castration anxiety of men. Dermoid cyst in different parts of body is also rarely reported in men. ${ }^{6}$ Till date only seven cases of vaginal dermoid cyst has been reported in literature. ${ }^{2}$ Stokes reported first case of dermoid cyst within hymen in 44-year-old women. ${ }^{3}$ Different authors have reported rare and vivid presentations of dermoid cyst of vagina and paravaginal spaces. ${ }^{8-10}$ Vaginal cysts like epidermal inclusion cyst, Bartholin cyst, Gartner duct cyst and paraurethral cyst are common findings in day-to-day gynecological practice. Paravaginal dermoid cyst though a rarity should always be kept a possibility. Vaginal dermoid cyst needs to be differentiated from epidermal inclusion cyst which usually occurs as skin appendages being buried in the wound at the time of episiotomy repair. Epidermal inclusion cysts remain the most common variety of vaginal cyst. ${ }^{11}$ Present patient 28 -year $\mathrm{P}_{2} \mathrm{~L}_{2}$ presented with pelvic pain, feeling of pressure with heaviness in perineum and dysparenia. Pelvic pain, pressure and evidence of a pelvic perineal tumour may be presenting symptom and sign. ${ }^{12}$ Patient may either be asymptomatic or complain of dyspareunia or difficulty in inserting tampons or presents as a swelling protruding through vagina. ${ }^{3}$ Pre-operative diagnosis on MRI could not be made in present case due to absence of teeth/bones in dermoid cyst. Preoperative diagnosis may be difficult due to similar sonographic characteristics as of an epidermal inclusion cyst. $^{4}$ Transvaginal excision of paravaginal dermoid cyst under regional anesthesia remains treatment of choice as done in present case and other authors..$^{2-4,10}$ Premature rupture of dermoid cyst during surgery occurred in present case due to dense adhesions with rectum, as observed by Sharma et al. ${ }^{2}$ Ruptured dermoid cyst showed chessy putty material with tufts of hair in similarity to Sharma et al. ${ }^{12}$ Histopathology confirmed diagnosis of dermoid cyst showing cyst lined by stratified squamous epithelium with smooth muscle, mature neural tissue, keratin flakes and fibro collagenous stroma. Histopathology remains gold standard to confirm the diagnosis of vaginal dermoid cyst. $^{2,4,12}$ Long term follow-up is desired. Patients with complete resection of benign teratoma have excellent outcome. $^{12}$

\section{CONCLUSION}

Paravaginal dermoid cyst (benign mature teratoma) though rarest of rare must be kept for differential diagnosis of vaginal cysts-a common occurrence. Preoperative diagnosis may be difficult or missed on sonography in absence of teeth and bone tissue in dermoid cyst. Transvaginal excision under anaesthesia remains treatment modality of choice. Histopathological examination remains gold standard for retrospective diagnosis of paravaginal dermoid cyst. Follow-up till life is mandatory. Complete resection of paravaginal dermoid cyst (Benign teratoma) has an excellent prognosis.

\section{Funding: No funding sources \\ Conflict of interest: None declared \\ Ethical approval: Not required}

\section{REFERENCES}

1. Al-Shahrani MS, Heywood M. A rare case of vaginal dermoid cyst: A case report and review of literature. Biomed Res. 2006;17(2).

2. Sharma R, Rao KA, Nagraj S. A rare case of vaginal dermoid cyst: a case report and review of literature. Int J Infert Fetal Med. 2012;3:102-4.

3. Stokes JE, Rep JH. The etiology and structure of true vaginal cysts. Johns Hopkins Hosp Rep. 1899;7:10936.

4. Siu SS, Tam WH, To KF, Yuen PM. Is vaginal dermoid cyst a rare occurrence or a misnomer? A case report and review of the literature. Ultrasound Obstet Gynecol: Official J Int Soc Ultrasound Obstet Gynecol. 2003;21(4):404-6.

5. Fujita K, A Kiyama N. Ishizaki M, Taraka S, Ohsawa K, Sugiyama H, et al. Dermoid cyst of colon. Dig Surg. 2001;18:335-7.

6. Longo F, Moremonti P, Mangone GM, DeMaria G, Califano L. Midline dermoid cyst of the floor of the mouth: Report of 16 cases and review of surgical techniques. Plast Reconstr Surg. 2003;112:1560-5.

7. Schuetz MJ $3^{\text {rd }}$, Elsheikh TM. Dermoid cyst (mature cystic teratoma) of the caecum. Histologic and cytologic features with review of the literature. Arch Pathol Lab Med. 2002;126:97-9.

8. Curtis AH. Transaction of societies: Chicago Gynecological Society. Surg Gynecol Obstet. 1913;16:715.

9. Johnston HW. A dermoid cyst of the vagina complicated by pregnancy. Canad Med Ass J.1939;41(4):386.

10. Hirose R, Imai A, Kondo H, Itoh K, Tamaya T. A dermoid cyst of the paravaginal space. Archynecal Obstet.1991;249:39-41.

11. Deppisch LM. Cysts of the vagina. Obstet Gynaecol. 1975;45:632-7.

12. Lukanovic A, Patrelli TS. Retroperitoneal mass with ischiorectal fossa extension: diagnosis, clinical features and surgical approach. A literature review starting from a rare clinical care of primary retroperitoneal dermoid cyst. Europ J Gynaecol Oncol. 2010;31(6):709-3.

Cite this article as: Bhatia R, Mohi MK, Gupta A, Goyal S. Para vaginal dermoid cyst: a rare occurrence. Int J Reprod Contracept Obstet Gynecol 2019;8:776-8. 